\title{
WAFFEN ALS GRABBEIGABE IM RAUM DER OBEREN UND MITTLEREN DONAU WÄHREND DER FRÜH- UND MITTELBRONZEZEIT
}

\author{
W O L F G A N G D A V I D
}

\begin{abstract}
Weapons in Graves in the Upper and Middle Danube Region During the Early and Middle Bronze Age. Weapons and especially the combination of different types of weapons in graves usually serve as a starting point for considerations regarding armament and fighting style. On the basis of regional or temporal differences of the weapons present in the graves and their combination, changes in the way of fighting are deduced. In addition, quantitative differences in the equipment of graves with weapons are often used by others to try to prove differentiated gradations in the social rank of the buried. Apart from the fact that at least some of the weapons can be ceremonial or ceremonial weapons or - especially arrowheads or spears - hunting or competition weapons and not the weapons actually or primarily used in battle, it is problematic to draw direct conclusions from the graves' inventory about the existence of weapons in this world.
\end{abstract}

Keywords: Central Europe, Bronze Age, thrust weapon, slash weapon, long-range weapon, social ranking.

Mangels schriftlicher oder bildlicher Darstellungen müssen Überlegungen zur bronzezeitlichen Bewaffnung und Kampfesweise von denjenigen Waffen ausgehen, die in Gräber gelangten oder als Bestandteil von Depotfunden geopfert, versteckt oder aus anderen Gründen niedergelegt, vergraben oder versenkt wurden. Hinzu kommen Waffen oder Waffenteile, die im Kampf oder bei Unglücken verloren gingen. ${ }^{1}$ Dabei ist jedoch zu beachten, dass die Bestattungs-, Beigaben- und Deponierungssitten der Früh- und Mittelbronzezeit im Donauraum durch regional- und zeitspezifische Unterschiede sowie durch einen wiederholten Wandel gekennzeichnet sind. ${ }^{2}$ Infolgedessen wurden Waffen weder in jeder der verschiedenen regionalen Kulturgruppen noch kontinuierlich in Graboder Depotfunden überliefert. ${ }^{3}$ Zudem spiegelt die Waffenausstattung im Grab nur bis zu einem gewissen Grad die Bewaffnung in der "lebenden" Kultur wider, da die Auswahl der Beigaben im Rahmen des Totenrituals aus uns weitestgehend unbekannten Gründen erfolgte. ${ }^{4}$

In diesem Zusammenhang geben Funde aus Siedlungen wie beispielsweise die Gußform einer Nackenkammaxt vom Typ Apa-Nehoiu aus der mehrschichtigen Věteřov-Siedlung von Waidendorf-
-Buhuberg, oder das Fragment einer ansonsten nur in Depotfunden überlieferten im Hajdúsámson-Stil (Stilvariante Turda-Zajta) verzierten Nackenscheibenaxt aus der Füzesabony-Otomani-Siedlung von Nižná Myšla aufschlussreiche Hinweise auf die Auswirkungen der jeweiligen zeit- oder kulturgruppenspezifischen Sitten auf die Überlieferung der materiellen Kultur. ${ }^{5}$ Die mögliche Bedeutung von gänzlich aus Holz oder anderem vergänglichen Material bestehenden Lanzen, Speeren, Pfeil und Bogen, Schleudern, Keulen und Knüppeln ist aufgrund weitgehender Nichterhaltung hingegen nur in Ansätzen abzuschätzen.

Im oberen und mittleren Donauraum sind in Gräbern der frühen Frühbronzezeit (BA1a) an potentiellen Waffen nur Dolchklingen und Pfeilspitzen belegt. Während der Dolch, ein Multifunktionsgerät, das als solches auch in Frauengräbern belegt ist, als Stichwaffe auf kurze Distanz während der gesamten Bronzezeit überliefert ist, finden sich Pfeilspitzen vorübergehend weder in Grab- noch in Depotfunden der Horizonte BA2a-älter bis BA2c-älter, sondern erst wieder in solchen ab der Phase BB-älter (David 2014, 191-194).

Hiebwaffen wie Randleistenbeile, Meißel oder Schaftlochäxte erscheinen erstmals in der

1 David 2014; Harding 2007; Jockenhövel 2006; Sicherl 2004.

2 Zur verwendeten chronologischen Gliederung und Terminologie der Stufen BA2 und BB siehe David 1998b, 305-332, 367 f., Abb. 14; 15; 1998c, Beilage 1; 2002a, 230-234, 260-265, 344-358, 366 f., 388-390, 910 f., Beilage 1; Abb. 5: 8, 9; 2015, 90-92; 2019, 91, Abb. 4; David u. a. 2017; David-Elbiali/David 2009.

3 David 1998a, 256-260; 1998c, 108-110, 122 f.; 2002b, 86-88; 2009; 2015.

4 David 2014, 189-194; Sicherl 2004, 210-219. Zu intentionell beschädigten und unvollständig ins Grab gelangten Dolchklingen Bátora 2009b, 236, 238, 253, 259, Abb. 11: 1; $14: 1$.

5 Bátora 2009a; David 2002a, 209 f., 423 (NS 102), 431 (NK 30); 2013, 94, 112, 115 f., 120 (Nr. 32), 133, 135, 137 f., Taf. 2; Karte 2: 2; 4: 2; 5: 2; Szatmári 2018. 

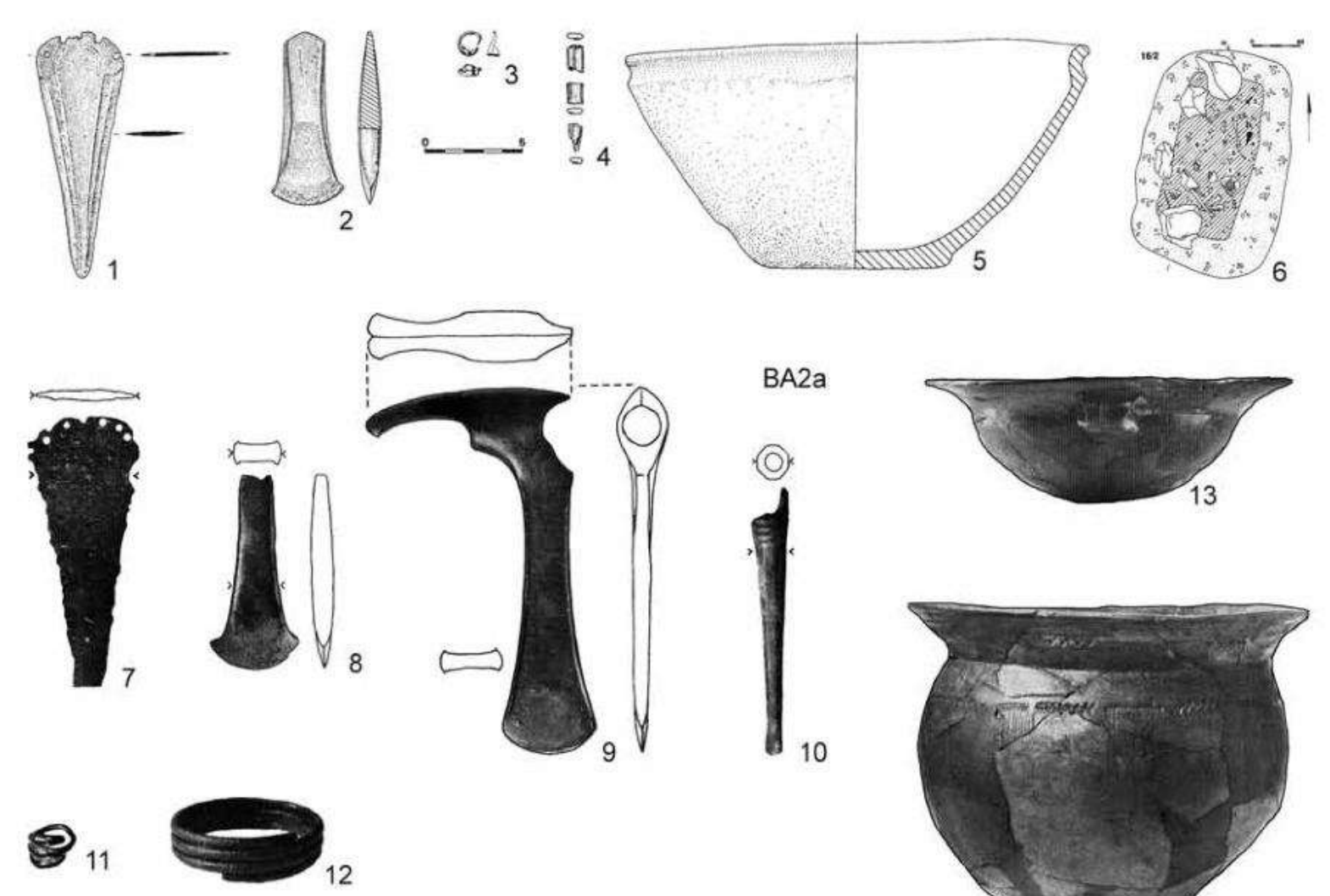

10
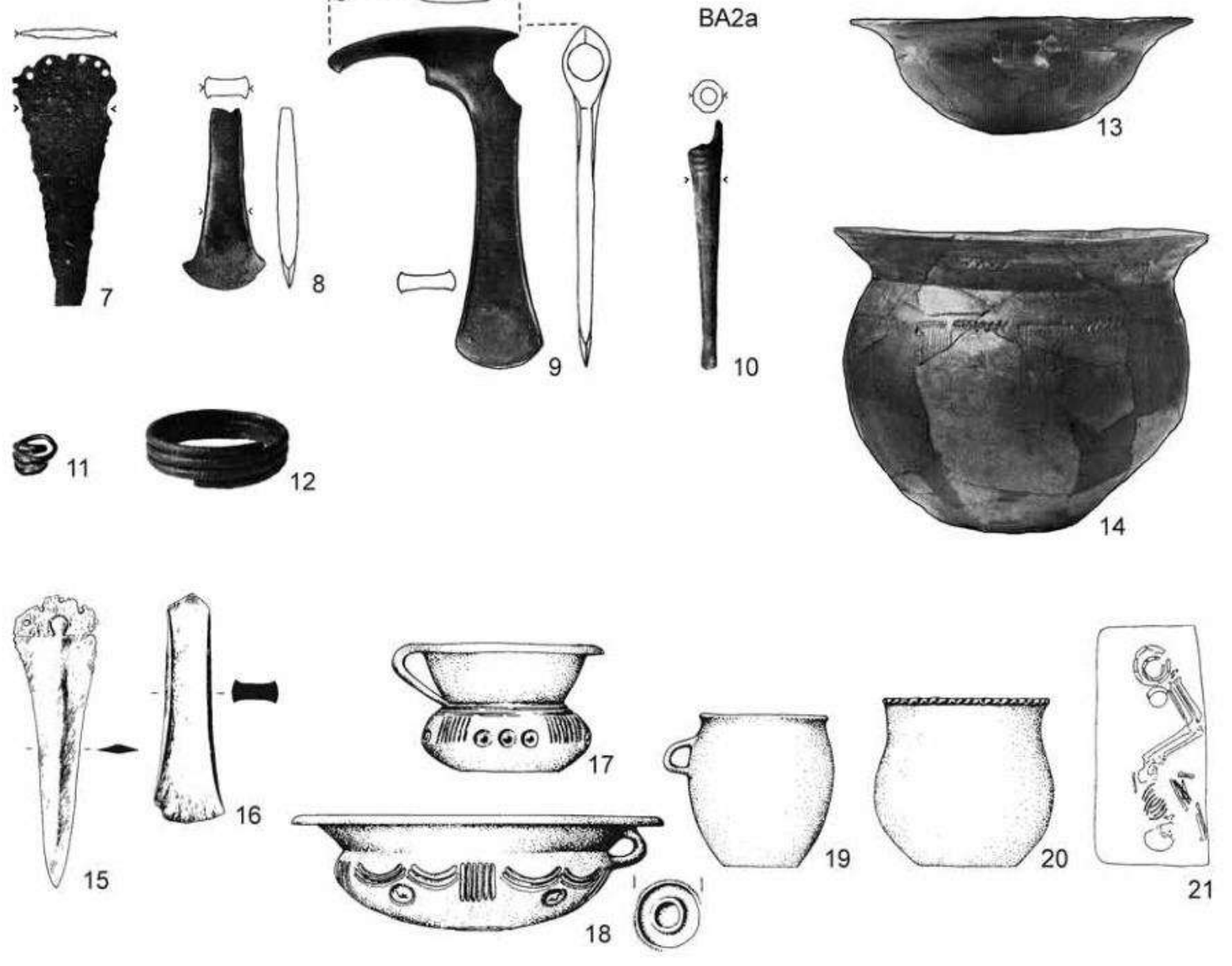

Abb. 1. Grabfunde der Stufe BA2a. 1-6 - Franzhausen I, Grab 16; 7-14 - Balatonakali; 15-21 - Tiszafüred-Majoroshalom, Grab B 176 (nach Kovács 1982; Neugebauer/Neugebauer 1997; Torma 1978).

entwickelten Frühbronzezeit (BA2a) in Gräbern (Abb. $1 ; 2) .{ }^{6}$ Schaftlochäxte aus Metall sind in Bestattungen der Maros/Mureş-Kultur (Deszk A, Grab 2; Battonya, Gräber 92, 122) und der Kultur der Pannonischen Inkrustierten Keramik (Balatonakali) belegt (Abb. 1: 9). ${ }^{7}$ Steinerne Schaftlochäxte fanden sich in Gräbern der Koštany-Kultur (Vala-
liky-Všechsvätých, Grab 49), der Füzesabony-Otomani-Kultur (Hernádkak, Grab 39), der Maros/ Mureş-Kultur (Szőreg, Gräber 40, 114), der Vatya-Kultur (Kulcs, Grab 60; Ercsi-Sinatelep, Grab 22), der südwestslowakischen und mitteldeutschen Aunjetitz-Kultur (Velký Grob, Grab 19; Helmsdorf; Leubingen; Österkörner), der Unterwölblinger

6 David 1998c, 113-117; 2014, 190, Abb. 3: 10, 14, 16-18; David-Elbiali/David 2009, 319-322, Abb. 3: H, I, L; 4: H, I, K.

7 Bóna 1975, 101, Taf. 92: 10; David 2002a, 311-313, 428 (SL 11, 12), Taf. 56: 1, 4; 237: 3; 238: 1; 2013, 96 f., 108,117 (Nr. 11, 12), 118 (Nr. 5), Abb. 5: 6, 7; Kiss 2020. 
Gruppe (Unterwölbling, Grab 25; Franzhausen I, Gräber 107, 782, 840) und der Ries-Gruppe (Baldingen, Grab 1193). ${ }^{8}$ Weitere sind aus Siedlungen wie beispielsweise Gyulavarsánd-Laposhalm oder Tiszafüred-Ásothalom bekannt (Bóna 1975, 137, 162, Taf. 150: 1, 16, 17; 151: 4; 197: 1). Erwähnt sei ferner der kugelförmige marmorne Keulenkopf aus Királyszentistván/Grab 12 (Bóna 1975, 220, Taf. 222: 6). Als effektive Hiebwaffen nutzbar waren auch Hacken oder Hämmer aus Geweih, die in Gräbern bis in die klassischen Phase der Füzesabony-Otomani-Kultur (BA2b-c) vorkommen (z. B. Nižná Myšla, Grab 363). ${ }^{9}$

Während die Beilklingen in Gräbern des älteren Horizontes der entwickelten Frühbronzezeit (BA2a-älter) wie z. B. Valaliky-Všechsvätých/Grab 47, Hernádkak/Grab 96a, Tiszafüred-Majoroshalom und Franzhausen I/Grab 16 relativ kurz sind (Abb. 1: 2, 8, 16; David 2002a, Taf. 240: 4, 6; 242: 2, 3; 243: 1, 2; 283: 1, 2), sind diejenigen in jüngeren Gräbern (BA2a-jünger-BA2b) in der Regel deutlich länger, und zwar länger als die mit ihnen kombinierten Dolchklingen (Abb. 2: 8, 16, 21; 3: 7). ${ }^{10}$

Zusätzlich zu Dolchklinge und Axt fanden sich in Vedrovice-Zábrdovice ein Tüllenmeißel, in Balatonakali eine Schaftlochaxt mit verlängertem Nackenkamm (Abb. 2: 7-10; 2: 15-17). Das derartige Vorkommen mehrerer Waffen der gleichen Funktionsgruppe in einem Grab stellt eine Gemeinsamkeit dieser und anderer Bestattungen mit den sogenannten „Fürstengräbern“ der Aunjetitz-Kultur in Niederösterreich (Feuersbrunn), Mitteldeutschland (Helmsdorf, Osterkörner, Leubingen) und Polen (Łęki Małe) dar. ${ }^{11}$ Anhand gemeinsamer Waffen- und Trachtformen, zu denen auch goldene Locken- oder Schläfenringe gehören (Abb. 1: 3, 11; 2: 4) zeichnet sich überregional ein Horizont von Grabfunden ab, die in den unterschiedlichen Regionen jeweils zu den am reichsten ausgestatteten Gräbern der entwickelten Frühbronzezeit (BA2a-jünger) zählen. In Südbayern gehören Grab 13 (1970) von Alteglofsheim, weiter donauabwärts die infolge von Störungen nur unvollständig überlieferten Bestattungen 551 und 597 von Franzhausen I in diesen Kontext (Abb. 2: 1-4, 11-14). ${ }^{12}$

Auch aus der späten Frühbronzezeit (BA2b-BA2c) gibt es Gräber, die mehrere Hiebwaffen (Äxte, Beile, Meißel) und goldene Lockenringe enthalten, so wie z. B. Tiszafüred-Majoroshalom/Gräber B 75 und B 115, die in die klassische Phase der Füzesabony-Otomani-Kultur datieren (Abb. 4; David 2002a, Taf. 255; 257). Anstelle der üblichen, meist mit Dolchklingen kombinierten Beil- und Meißelklingen finden sich in Männergräbern der Horizonte BA2b und BA2c zwischen Niederösterreich beziehungsweise Südmähren und Ostungarn auch sogenannte Schaftröhrenäxte vom Typ Křtěnov (Abb. 3: 11, 16, 20) und Schaftlochäxte vom Typ Apa-Nehoiu (Abb. 4: 10). Während Gräber mit Nackenkammäxten vom Typ Apa-Nehiou bislang nur im östlichen Karpatenbecken belegt sind, ${ }^{13}$ kommen Schaftröhrenäxte vom Typ Křtěnov, und zwar solche des älteren BA2b-BA2c-zeitlichen Typs I, zwischen Niederösterreich und Ostungarn in Kontexten der Gruppen Věteřov-Böheimkirchen, Vatya, Füzesabony-Otomani, Maros/Mureş und der Pannonischen Inkrustieren Keramik vor. ${ }^{14}$

Gegen Ende der späten Frühbronzezeit (BA2cBB-älter) tragen die Waffen im östlichen Karpatenbecken zuweilen flächenfüllendes Ornament. Die an Merkmalen reiche Morphologie und das vielfältige Ornament erlauben es, die Entwicklung der Schwerter und Äxte in chronologisch fein differenzierten Etappen zu beschreiben. Verfolgt man nun das Auftreten der chronologisch sehr empfindlichen Varianten dieser Äxte, Dolche und Schwertern innerhalb geschlossener Funde, so wird offenbar, dass sich das Vorkommen von Waffen gegen Ende der späten Frühbronzezeit (BA2c$B B$-älter) vorübergehend von den Gräbern weg und hin zu Deponierungen à la Hajdúsámson, Apa, Nitriansky Hrádok, Křtěnov oder Ves Touškov verlagert (Abb. 5; David 2002a, 366 f., Abb. 5: 8, 9). So

8 Bátora 1982, 292, Abb. 38: 22; Benkovsky-PivovaroválChropovský 2015, 134, 180, Taf. 26: 8, 9; 245: 91, 15; Bóna 1975, 51, 103, 162, Taf. 12: 4; 116: 22; 121: 1; 163: 26; David 2002a, Taf. 241: 2; 278: 10, 13; 281: 8; 2014, 188, Anm. 7; Kaiser 1962, 53, Abb. 19: 2; Neugebauer/Neugebauer 1997, Taf. 446: Verf. 170, 1; 448: Verf. 107, 5; 569: Verf. 782, 3; 577: Verf. 840, 5.

9 Bóna 1975, 102, 160, Taf. 85: 5; David 2002a, 39, 490 (SK 72), Taf. 249: 3, 911; Beilage 1; Olexa/Nováček 2015, 39, Abb. 16: 10; Ruckdeschel 1978, 81, 82 (K 91), Taf. 27: 1-3.

${ }^{10}$ Zum Beispiel David 2002a, Taf. 274; 275: 4, 5; 276: 7, 8; 277; 278: 7-9; 279: 3, 4; 281: 10-12, 14-18; 292; 295: 8, 9; 299; 318; 325; 331; 332; 2014, 191 f., 198, 201, Abb. 3: 9, 10, 15, 16; 4: 4, 5; 7: 5-7; 9: 8, 9; 10: 4, 6. Vgl. Sicherl 2004, 138-140, 193.

${ }^{11}$ David 2002a, 450 (A 26), 458 (D 7, D 13), 476 (PL 13), Taf. 277-281; Zich 2016, Abb. 2-5; 9; 11-13. H. Meller stellte für die klassische Phase der Aunjetitzer Kultur in Mitteldeutschland die Hypothese auf, dass es sich bei den in den „Fürstengrabhügeln“ von Leubingen und Helmsdorf Bestatteten um Herrscher und militärische Befehlshaber handelt, die bereits in der der entwickelten Frühbronzezeit (BA2a-jünger) über stehende Truppen professioneller Soldaten verfügten, die standardmäßig mit Beilen bewaffnet waren und von Dolch- und Stabdolchträgern kommandiert wurden (Meller 2015, 244-250; 2017, 1537-1542; 2019, 53-65)

12 David 1998c, 113-117, Abb. 1; 2; 2002a, Taf. 273-285; 286: 3; 2014, 190, 195, Abb. 3: 5-16.

${ }^{13}$ David 2002a, 283-326, 429-432, Taf. 59-67; 254-258; Karte 13; 2013, 99, 102, 137, Karte 4: 2.

${ }^{14}$ David 2002a, 327-367, 432-436, Taf. 70-74; 251; 252; 292: 5-8; 296; 298: 6-9; Karte 15; 16; 2008, 220-223, Abb. 18. 


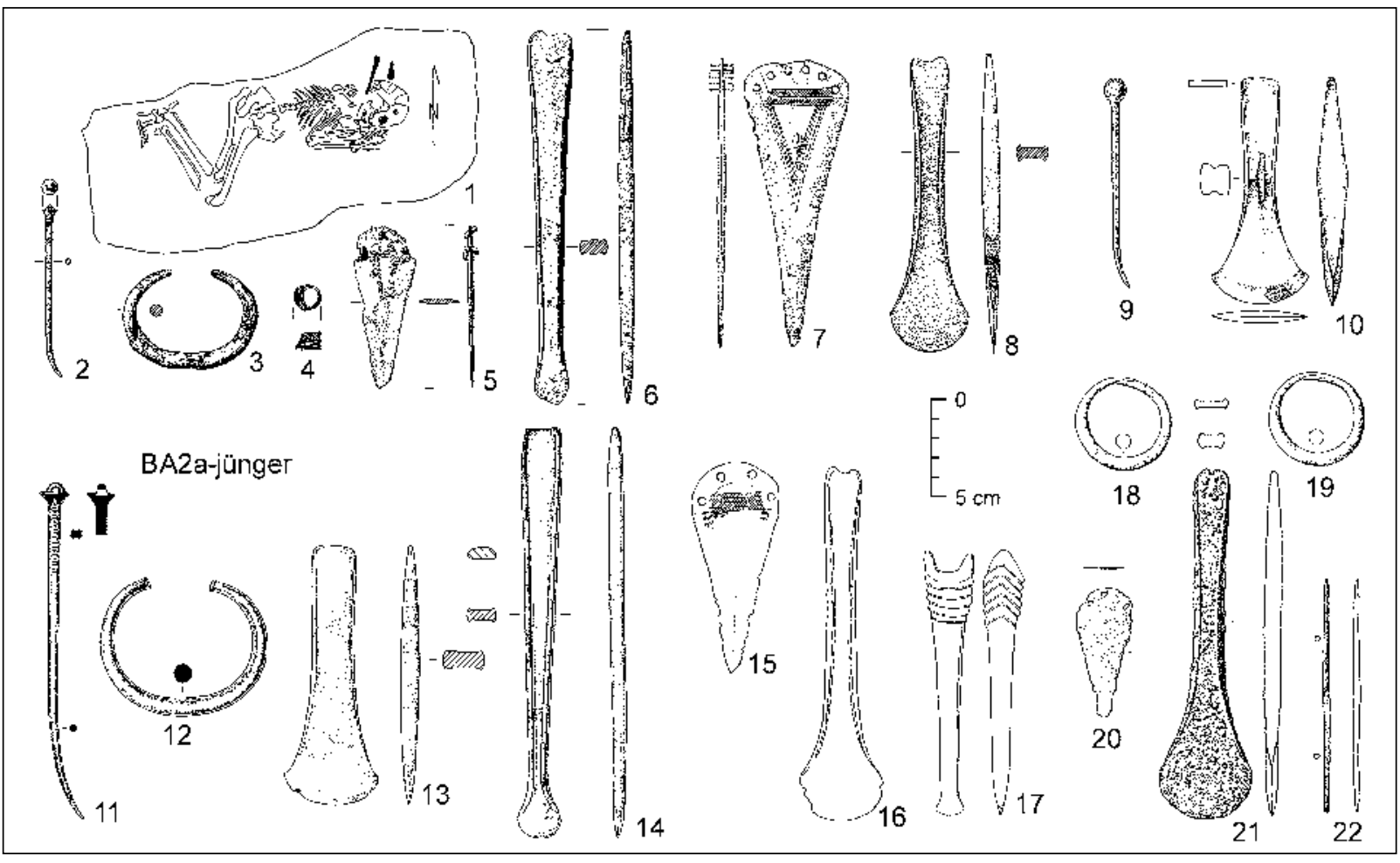

Abb. 2. Grabfunde der Stufe BA2a-jünger. 1-6 - Alteglofsheim, Grab 13/1970; 7, 8 - Mötzing, Grab 20; 9, 10 - Bernolákovo, Grab 2; 11-13 - Franzhausen I, Grab 551; 14 - Franzhausen I, Grab 597; 15-17 - Vedrovice-Zábrdovice; 18-22 Elsarn, Gem. Straß im Straßertale (nach Benkovsky-Pivovarová/Chropovský 2015; David 2002a; Rieckhoff 1990; Říhovský 1992; Schröter 1998).

kommen diejenigen Ausprägungen der Äxte und Schwerter, die für die Stufe BB-älter typisch sind - wie zum Beispiel die Schaftröhrenäxte des jüngeren Typs II (Křtěnov) oder die Schwerter der Typen Hajdúsámson und Oradea - ausschließlich in Depotfunden und niemals in Gräbern vor (Abb. 5: 1, 2, 5, 9, 10). In Depots dieses Zeithorizontes (BB-älter), welcher in die postklassische Phase der Gyulavarsánd-Otomani-, Füzesabony-Otomani-, Vatya- und Madarovce-Kultur datiert, sind auch erstmals Nackenscheibenäxte belegt (Abb. 3: 3). Jüngere Ausprägungen der Nackenscheibenäxte sind später Bestandteil von Männergräbern der entwickelten Hügelgräberkultur (BC1-BC2) zwischen dem Banat im Südosten sowie Bayern und Böhmen im Nordwesten (Abb. 6: 3; 8: 5; 9: 3, 12). ${ }^{15}$

Aus dem spätfrühbronzezeitlichen Horizont BB-älter sind Männergräber mit Waffenbeigabe, die sich mit denen der Horizonte BA2a-BA2c oder $\mathrm{BB}$-jünger-BC2 vergleichen ließen, bislang gänzlich unbekannt. Es gibt zwar Einzelfunde der in den Depots vorkommenden Waffentypen - wohl meist Einzeldeponierungen -, aber es lassen sich in denjenigen Fundregionen des Donauraumes, in denen es zu derartigen Deponierungen von Waffen kam, keine Männergräber des Horizontes BB-älter nennen, welche Waffen genau derselben Typen und Varianten, wie sie in den Depots vorkommen, enthalten. Lediglich außerhalb des donauländischen Kreises, an dessen westlicher und nordwestlicher Peripherie, gibt es Männergräber der Phase BB-älter mit Kurzschwertern, die im Umriß denjenigen der Dolchklingen und Vollgriffschwertern der Typen Kelebia, Hajdúsamson, Oradea oder Vajska gleichen: so zum Beispiel Bex und Varen im Wallis sowie Drouwen, Rastorf/Grab 5 und Ziegenberg im Sögel-Wohlde-Kreis. ${ }^{16}$

Erst das Formengut von Depots, die innerhalb der Depotfundgruppen von Hajdúsámson-Apa-Ighiel-Zajta oder Dunaújváros-Kosziderpadlás zu den jeweils jüngeren zählen (z. B. Zajta, Makov-Gregušovci, Áporka) läßt typologische Bezüge zu Grabfunden erkennen, und zwar zu solchen des Horizontes BB-jünger oder „Lochham-Wetzleinsdorf-Letkés“ (Abb. 6). Für die Grabfunde bedeutet dies, dass der älteste Horizont (BB-jünger) mittelbronzezeitlicher Männergräber mit Waffenausstattung wie Letkés/Grab 37, Pitten/Grab 41 oder Zurndorf

\footnotetext{
${ }^{15}$ David 2002a, 261-264, 312, 357, 362-367, Abb. 3: 17; 4: 4; 5: 6, 8, 9; 2013, 107-112.

${ }^{16}$ David 2002a, 392 f., 458 (D 16, 23), Taf. 333-335; David u. a. 2017, 209, Abb. 9: J; David-Elbiali/David 2009, 325, Abb. 6: H, I.
} 


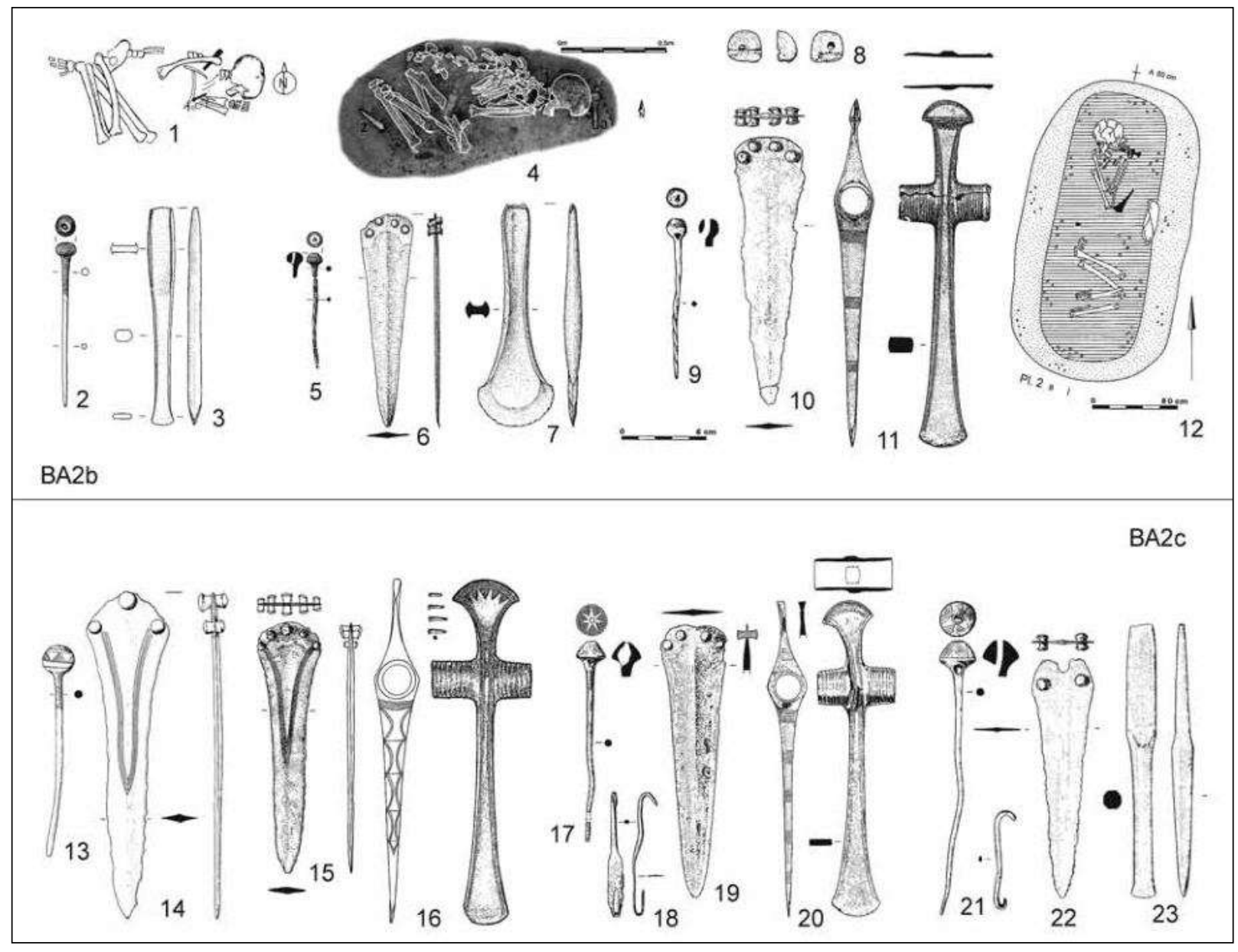

Abb. 3. Grabfunde der Stufen BA2b und BA2c. 1-3 - Mintraching-An der Pfatter, Grab 2; 4-7 - Osterhofen-Am Stadtwald, Stadt Altenmarkt, Grab 10; 8-12 - Franzhausen II, Grab 711; 13, 14 - Statzendorf, Grab 9; 15, 16 - Borotice, Hügel 2, Grab II; 17-20 - Gemeinlebarn F, Grab 150; 21-23 - Franzhausen II, Grab 649 (nach Massy u. a. 2018; Neugebauer 1991; Neugebauerl Gattringer 1989; Ruckdeschel 1985; Schubert 1973; Stuchlík 2006).

nicht direkt auf die Gräber des Horizontes BA2c folgte (Abb. 3: 13-23; 6). Vielmehr stehen zwischen den Kriegergräbern der späten Frühbronzezeit (BA2b-BA2c) und denen der frühen Mittelbronzezeit (BB-jünger) typologisch, stratigraphisch und chronologisch die Waffendepots des Horizontes BB-älter wie Hajdúsámson, Apa, Szeghalom oder Nitriansky Hrádok im Karpatenbecken sowie Křtěnov, Ves Touškov oder Greding in Böhmen und Bayern (Abb. 5). ${ }^{17}$

Der älteste Horizont mittelbronzezeitlicher Gräber mit Waffenbeigabe, der Horizont Lochham-Wetzleinsdorf-Letkés (BB-jünger), ist zwar weiträumig zwischen dem Karpatenbecken und der Schweiz zu fassen, jedoch quantitativ weitaus weniger ausgeprägt wie der nachfolgende Horizont der entwickelten Mittelbronzezeit beziehungsweise Hügelgräberkultur (BC1). Die bereits aus der entwickelten und späten Frühbronzezeit bekannte Kombination von Hiebwaffe und Dolch ist auch in Gräbern der älteren Mittelbronzezeit (BB-jünger; Abb. 6: 15-18, 27-29), ${ }_{1}^{18}$ der entwickelten Mittelbronzezeit $(\mathrm{BC} 1)^{19}$ sowie der jüngeren Mittelbronzezeit (BC2) belegt (Abb. 9: 27-29) und wird zuweilen von Pfeilspitzen begleitet (Abb. 6: 21-23; 7: 4-6, 18; 8: 6-10, 26-35; 9: 14-18). ${ }^{20}$

\footnotetext{
${ }_{17}$ David 1998c, 122 f.; 2002a, 366 f., 393, 407 f., 413 f., Abb. 5: 8, 9; 2002b, 65-67, 86-88; David u. a. 2017, $206-211$.

18 Čujanová-Jílková 1970, 33, Taf. 2: A; David 2002a, Taf. 318; 325: 1-9; 328: 5-7; 329: 3-12; 330-332; Wels-Weyrauch 2015, 78 (Nr. 183), 81, 82 (Nr. 201, 203), 91 (Nr. 280), Taf. 17: 183; 19: 201, 203; 21: 242; 24: 280.

19 Čujanová-Jílková 1970, 24, 121, Abb. 40: H; 94: B; Hochstetter 1980, 135 (Nr. 132), Taf. 47: 5-8; Koschik 1981, 181, 202,203 (189 B), 216, Taf. 82: 1-5; 109: 6-12; Torbrügge 1959, 181 (Nr. 237 D), Taf. 48: 1-3; Wels-Weyrauch 2015, 80 (Nr. 195), 104 (Nr. 393 ), 106 (Nr. 408 , 409), 107 (Nr. 421), Taf. 18: 105; 32: 393, 408, 409; 33: 421; Wenzl 1907, 99 f., Taf. 28; 32: 1-3.

${ }^{20}$ Zum Beispiel Mantlach, Hügel 2; Kronstorf, Hügel 4; Kiskunmajsa; Borotice, Hügel 15/Grab II (David 2002a, Taf. 343: 1-6; 345: 1-3; Stuchlík 2006, 93 f., Abb. 87; 88; Torbrügge 1959, 167, Taf. 43: 45-49, 51-53).
} 


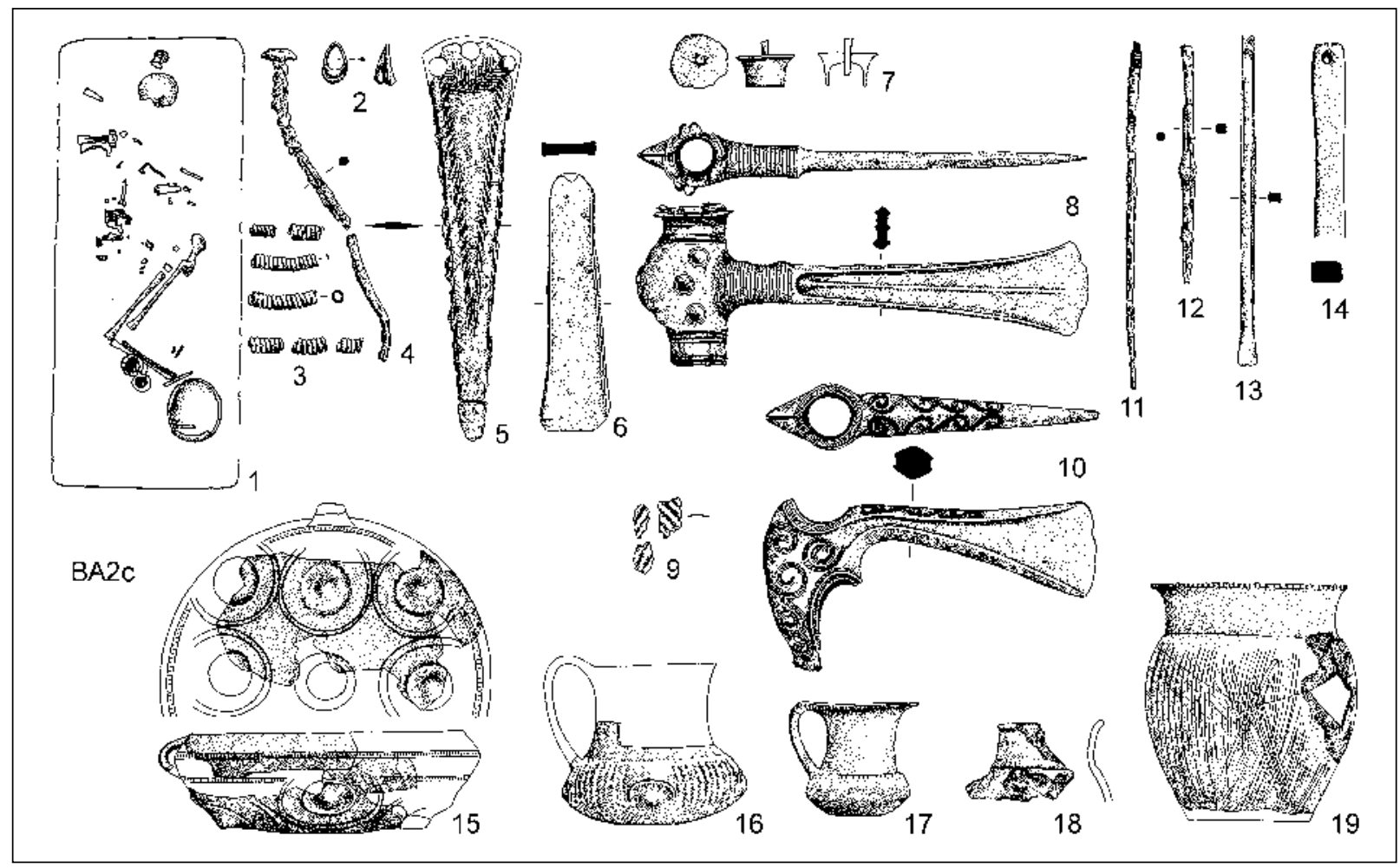

Abb. 4. Tiszafüred-Majoroshalom, Grab B 115 (nach Kovács 1995).

Von der Kombination von Axt/Beil und Dolch ist die Kombination von Hiebwaffe und Kurzschwert zu unterscheiden. Denn bei einem Langdolch oder einem Kurzschwert ab etwa 23-25 cm Klingenlänge handelt es sich aufgrund der relativen Schmalheit der Klinge bereits um spezialisierte Stichwaffen mit größerer Reichweite. Im Donauraum und auch im angrenzenden Böhmen ist die Kombination von Axt/Beil und kurzem Schwert in Gräbern erstmals im Horizont BB-jünger sicher belegt (Abb. 6: 2, 3, 9, 10). ${ }^{21}$ Sie ist auch noch in der entwickelten Hügelgräberbronzezeit (BC1) anzutreffen..$^{22}$ Daneben erscheinen in Gräbern desselben Horizontes auch deutlich längere Schwerter mit Griffplatte oder mit Griffzunge in Kombination mit Randleisten-, Absatz- oder Lappenbeilen oder auch mit den auffälligen Nackenscheibenäxten. ${ }^{23}$ Letztere finden sich zusammen mit Schwertern auch noch in Leitfunden des nächstjüngeren Horizontes BC2 (Abb. 9: 1, 3, 11, 12). In die gleiche Zeit (BC2) gehört auch das Grab von Grödig bei Salzburg mit Vollgriffschwert, Lappenbeil und einzelner Pfeilspitze (David 2002a, 226, 258, 427, 449, 455, Taf. 351; 353).

Die Kombination von Schwert und Axt/Beil wird in Tachlovice und anderen Gräbern aus der frühen, entwickelten und jüngeren Mittelbronzezeit oft durch einen Dolch ergänzt, dessen Klinge üblicherweise kürzer als das Beil ist (Abb. 7: 8-10, 15-17; 9: 1-3). ${ }^{24}$ Bezüglich der Funktion der Dolche ist der Befund von Štáhlavy-Hájek (Stiahlau) - Hügel 48 - aufschlussreich, denn die Dolchklinge lag zu Füßen des Toten in einer Tonschüssel, die laut chemischer Analyse Reste von fleischlicher Nahrung enthalten hatte (Abb. 7: 9, 12; Čujanová-Jílková 1970, 96, Abb. 111: 11, 20). Wie bereits an anderer Stelle erwähnt, dürfte auch in anderen Fällen, wo der Befund weniger eindeutig ist oder gar fehlt, bei derartigen kurzen Dolchklingen weniger die mögliche Nutzung als Waffe die eines Multifunktionsgerätes in Betracht gezogen werden. Und falls man die Pfeilspitzen als einen Hinweis auf den Einsatz von Pfeil und Bogen als Jagdwaffe in Betracht zieht, dann könnte der Dolch auch als Waidgerät gedient

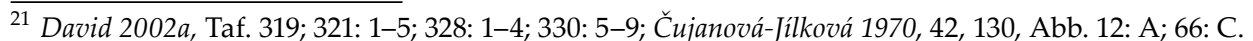

22 Čujanová-Jílková 1970, 40, 86, Abb. 15: 4, 5, 7, 8; 59: A; Torbrügge 1959, 149, Taf. 33: 1, 2; Wels-Weyrauch 2015, 115 (Nr. 481 ), Taf. $37: 481$.

${ }^{23}$ Čujanová-Jílková 1970, 84, Abb. 60: A; David 2002a, 225 f., 449 (A 8), 454 (CZ 28), Taf. 326; 341-342; 348.

24 Čujanová-Jílková 1970, 20, 38, 42, 96, Abb. 12: B; 15: A; 17: A; 111: 10-12, 16-20; David 2002a, 454 (CZ 14), 461 (D 80); 2014, 198-201, Anm. 46, Abb. 9: 7-11; 10: 1-8; David u. a. 2017, 213, Abb. 13: 1-8; Schauer 1971, 51, 52 (Nr. 143), Taf. 18: 143; 130: A; Wels-Weyrauch 2015, 93 (Nr. 292), 106 (Nr. 407), 130 (Nr. 603), Taf. 24: 292; 32: 407; 43: 603.
} 


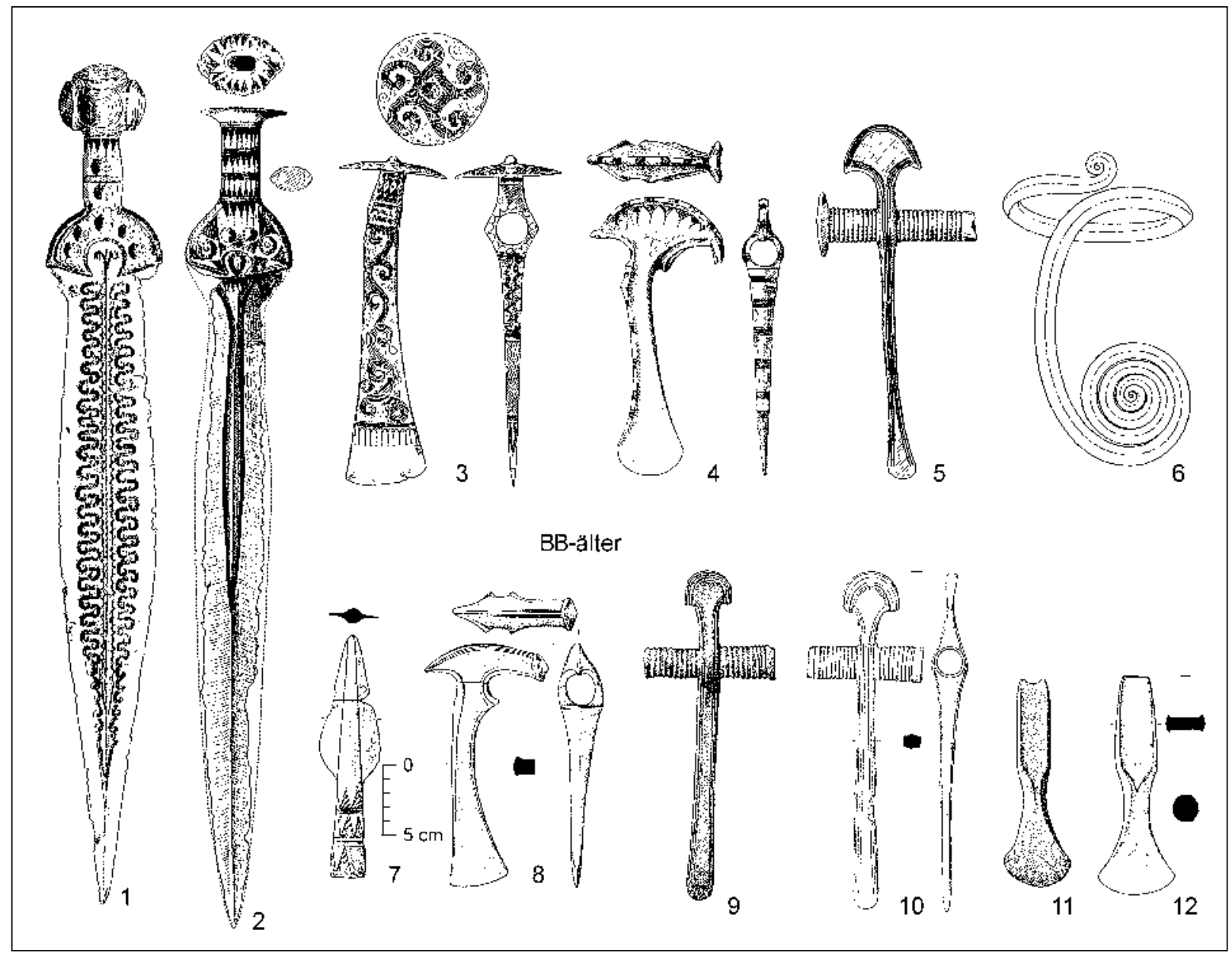

Abb. 5. Waffendepots der Stufe BB-älter. 1-6 - Apa, Depot; 7-12 - Nitriansky Hrádok-Zámeček, Depot aus Sektor D/2 (nach David 2002a; Popescu 1940; Schubert 1973).

haben. ${ }^{25}$ Im bekannten Männergrab aus Hügel E bei Asenkofen ist schließlich ein Messer an die Stelle des Dolches getreten (Abb. 9: 22).

In Anbetracht der voranstehend beschriebenen Ausstattungsmuster mag man sich die Frage stellen, was es bedeuten könnte, dass manche der Bestatteten nur mit Stichwaffe, andere nur mit Hiebwaffe, andere wiederum sowohl mit Hieb- und Stichwaffe bestattet wurden, und zwar insbesondere dann, wenn die Gräber auf ein und demselben Bestattungsplatz oder gar im selben Tumulus entdeckt wurden. Zeigt sich in den unterschiedlichen Ausstattungen eine Abstufung im Rang oder sind sie gar als Hinweis auf unterschiedlich bewaffnete Truppenkörper zu werten? Machte erst die Kombination von Hieb- und Stichwaffe den Mann als Krieger „komplett“? Und welche Rolle spielen die metallenen Pfeilspitzen dabei als Distanzwaffe für den Kampf und/oder die Jagd?

Hügel 39 von Sedlec-Hưrka verdeutlicht diese Problematik. Es handelt sich um den größten Grabhügel des Gräberfeldes mit mächtigem Steinbau, in dem sich fünf Bestattungen befanden. ${ }^{26}$ Drei von diesen - die Gräber 1, 2 und 4-sind Männergräber und enthielten allesamt Pfeilspitzen und Golddrahtspiralen in jeweils unterschiedlicher Zahl. Darüber hinaus fanden sich in Grab 2 außer drei Spiralringen aus Golddraht und drei Pfeilspitzen ein Bronzedolch in hölzerner Scheide und eine verzierte Scheibenkopfnadel (Abb. 8: 19-22, Pfeilspitzen nicht abgebildet). Der Tote in Grab 1 war hingegen mit vier Golddrahtspiralen, fünf Bronzepfeilspitzen, einem Dolch mit bronzenem Ortband, fünf Pfeilspitzen und zusätzlich einer verzierten Nackenscheibenaxt ausgestattet

\footnotetext{
${ }^{25}$ David 2002a, 455 (CZ 46), Taf. 354: 6-9; 2014, 198, Abb. 9: 1-6 („Hagenau“); David u. a. 2017, 212, Abb. 12: 1-6 („Hagenau“); Wels-Weyrauch 2015, 97 (Nr. 327), 130 (Nr. 602), Taf. 27: 327; 43: 602.

${ }^{26}$ Čujanová-Jílková 1970, 85 f., Abb. 57; 58: A; 1975, 76 f., 81-83, 98 f.; Hrala 1997, 172-174, 182 f., 467 f., Abb. 6; 17: 3; Taf. 3; 4: С̌ 72-90.
} 


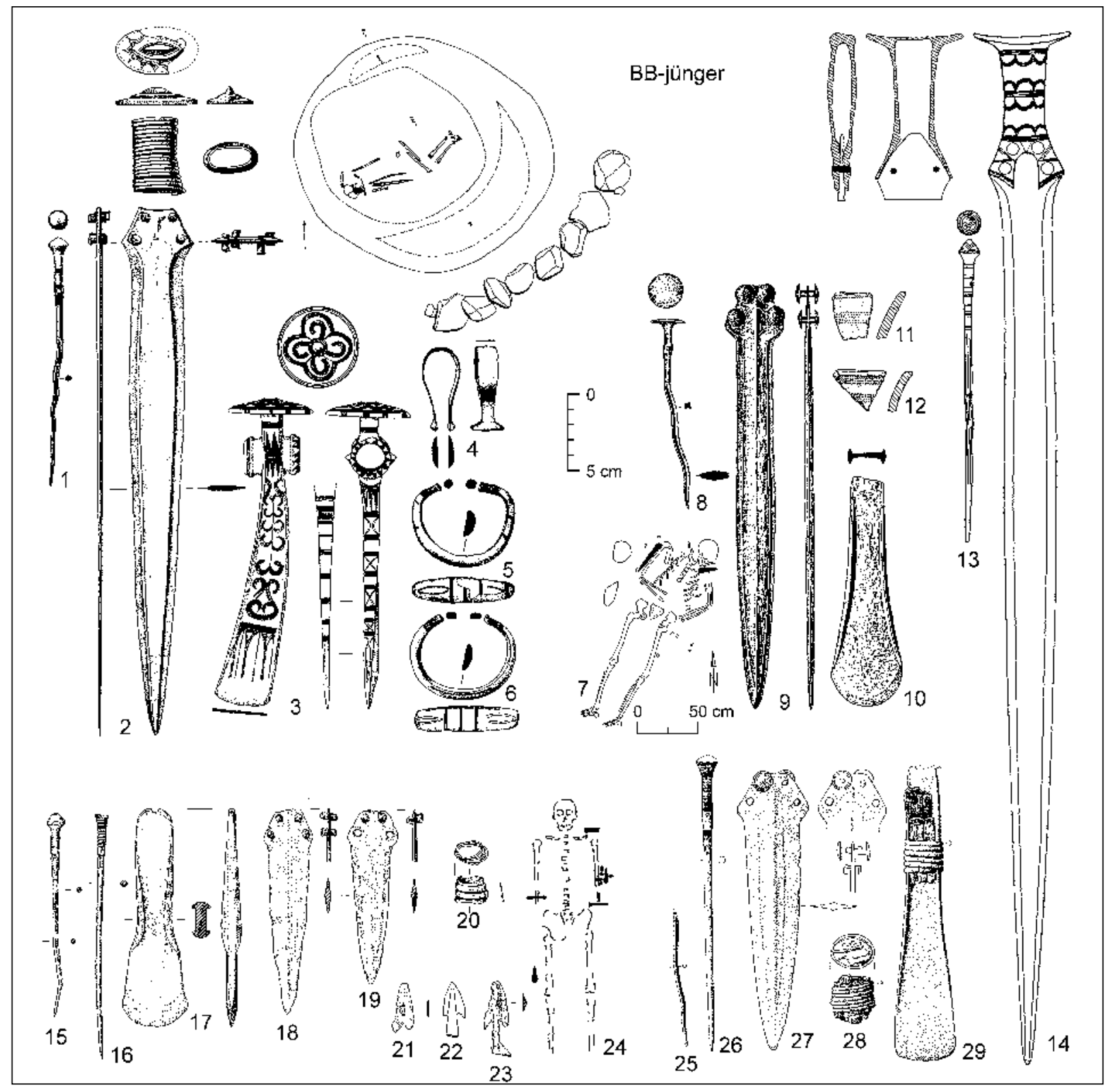

Abb. 6. Grabfunde der Stufe BB-jünger. 1-6 - Letkés-Kertész-földje, Grab 37; 7-12 - Pitten, Grab 41; 13, 14 - Zurndorf; 15-24 - Lochham, Hügel 10, Grab 2; 25-29 - Niederlauterbach-Geeichet, Gem. Wolnzach, Hügel 1, Grab 1 (nach Hampl/ Kerchler/Benkovsky-Pivovarová 1981; Koschik 1981; Kovács 1996; Ohrenberger 1953; Vahlkampf 1984; Wels-Weyrauch 2015).

(Abb. 8: 1-18). In Grab 4 fanden sich sogar sechs Golddrahtspiralen und zehn Bronzepfeilspitzen, aber weder Dolch noch Axt. Stattdessen waren dem Toten ein Schwert und an Goldobjekten außer den Drahtspiralen noch eine gewölbte Scheibe (Durchmesser $12 \mathrm{~cm}$ ) sowie ein in Bruchstücken erhaltenes Band aus dünnem Goldblech beigegeben worden (Abb. 9: 24-49). Es erscheint reizvoll und vielleicht sogar naheliegend, anhand der jeweils unterschiedlichen Ausstattung mit Waffen und Goldgegenständen für die Männergräber in Hügel 39 eine soziale Rangfolge zu rekonstruieren, in der Grab 4 die Spitzenposition einnimmt. Aber dies ist wohl zu einfach gedacht, denn im unmittelbar daneben liegenden Hügel 40 fand sich in einem der Gräber die Kombination von Schwert und zwei Beilen zusammen mit 14 Bronzepfeilspitzen und möglicherweise einem Spiralring aus Golddraht. ${ }^{27}$ Und auch in Hügel 9 derselben Nekropole wurde ein Körpergrab gleicher Zeitstellung (BC1) entdeckt, das zwar keine Goldfunde, 


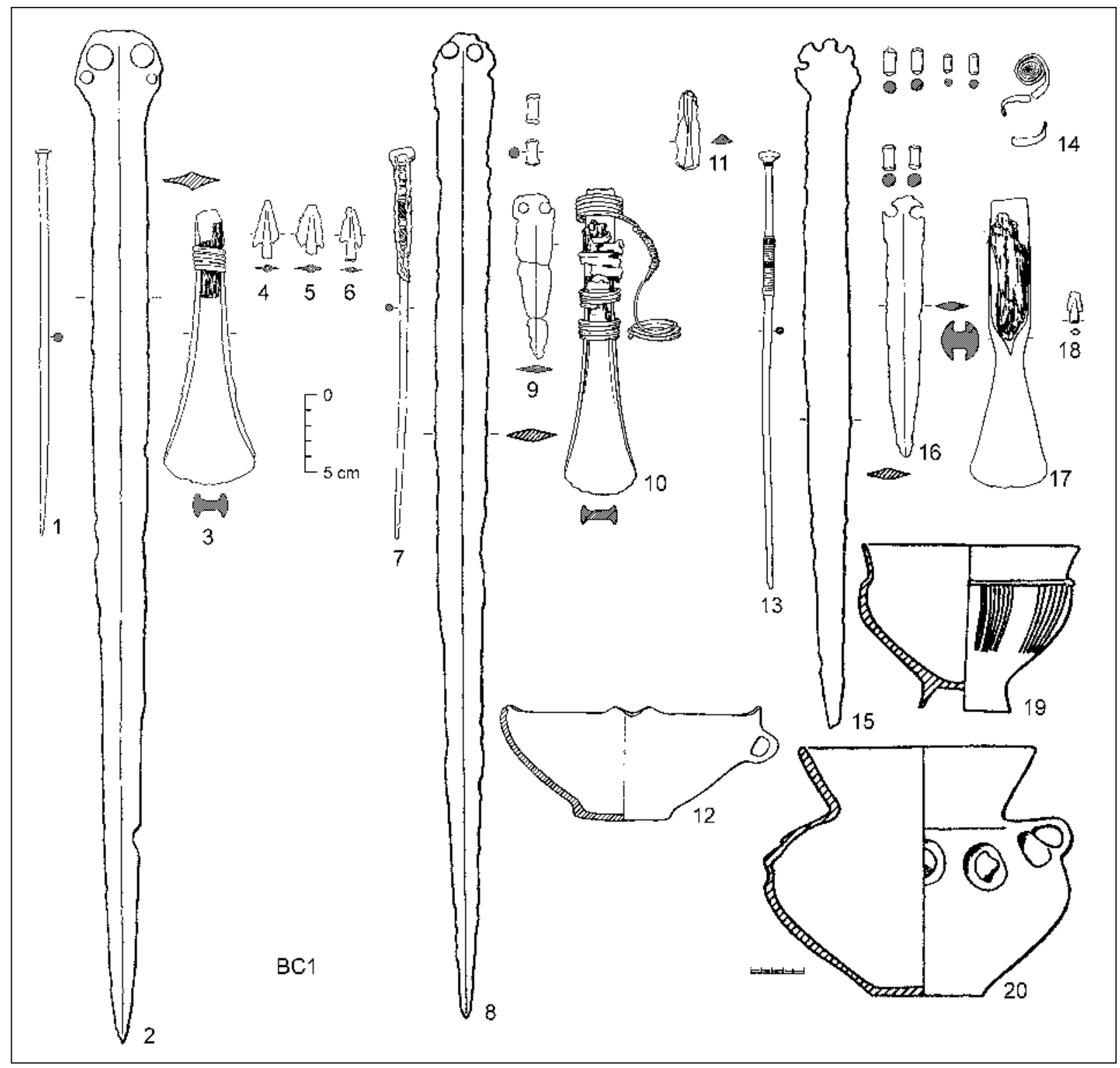

Abb. 7. Grabfunde der Stufe BC1. 1-6-Sedlec-Hůrka, Starý Plzenec, Hügel 9; 7-12 -Štáhlavy-Hájek, Hügel 48; 13-20 - Kbel, Hügel 4a (nach Čujanová-Jílková 1970).

jedoch außer sieben Pfeilspitzen auch die bekannte Kombination von Schwert und Beil enthält (Abb. 7: $1-6),{ }^{28}$ die in Hügel 39 hingegen nicht belegt ist. Dort verteilen sich Schwert, Axt und Dolch gewissermaBen auf zwei der drei mit goldenen Accessoires und Pfeilspitzen ausgestatteten Gräber (Abb. 8: 3-5, 25).

Zieht man vergleichbare Befunde von anderen Fundorten in die Betrachtung mit ein, dann sind hier zum Beispiel das Grab von Malnice oder diejenigen von Zelené/Hügel 8 und Třebívlice zu nennen, deren Inventare allesamt Schwert und Axt/Beil in Kombination mit Spiralringen oder einem Blech- streifen aus Gold umfassen (Abb. 9: 19, 20; David 2002a, 454 f., Taf. 348; 351: 1-6). In Zelené/Hügel 8 und Třebívlice fanden sich außerdem Pfeilspitzen wie in den erwähnten Gräbern der Hügel 9, 39 und 40 von Sedlec-Hůrka (Abb. 8: 6-10, 26-35; 9: 14-18). Zwei Schläfen- oder Lockenringe aus doppeltem, spiralig gewundenen Golddraht - jedoch keine Pfeilspitzen - gehören zusammen mit Schwert, Dolch und Axt schließlich auch zum Inventar des Grabes von Singenbach-Weilerau in Oberbayern, einem Leitfossil der Stufe BC1 nach Paul Reinecke (David 2014, 198, 200 mit Anm. 48, Abb. 9; Reinecke 1905, 110-112, Abb. 1). 


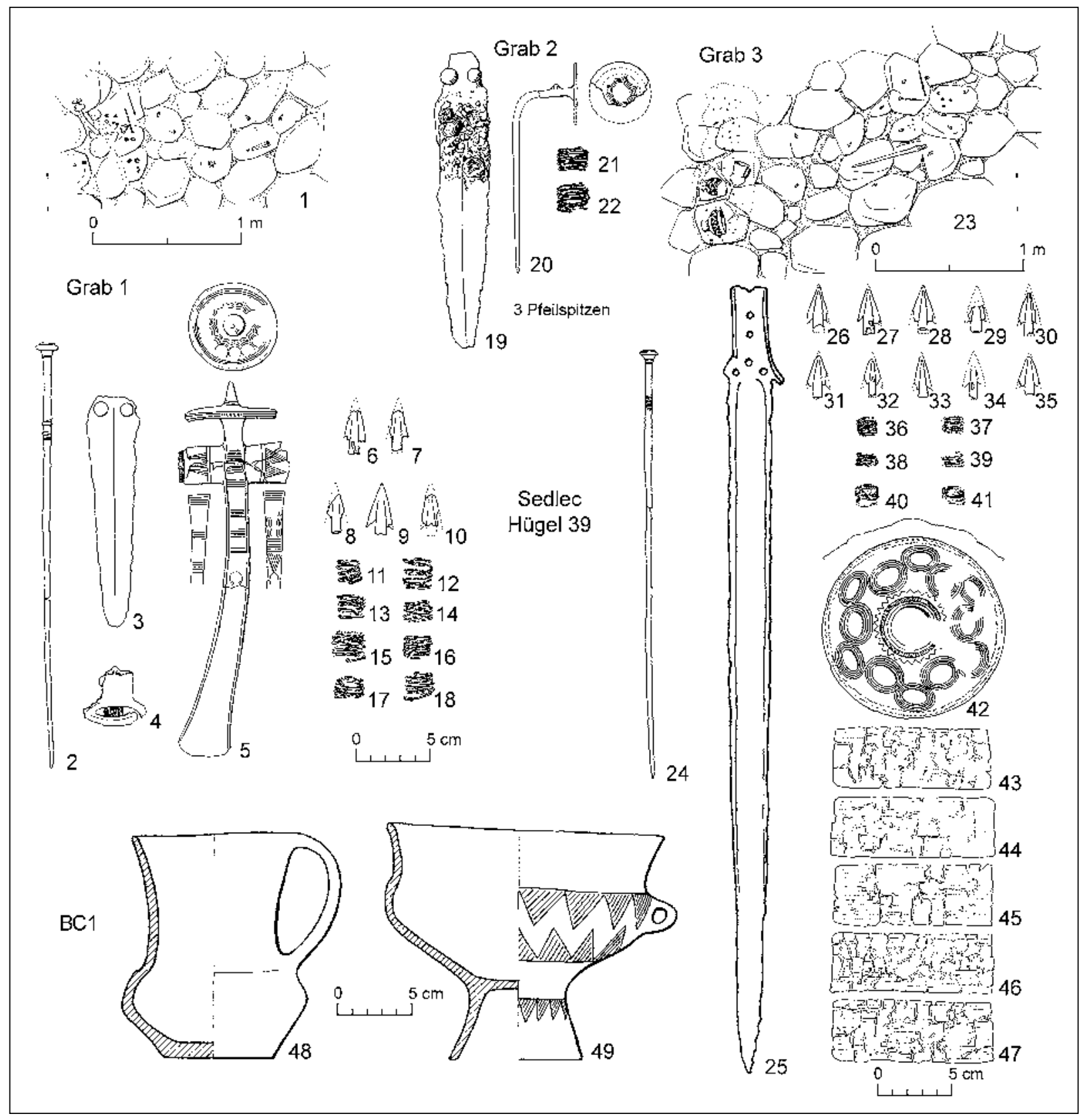

Abb. 8. Sedlec-Hůrka, Starý Plzenec, Hügel 39. 1-18 - Grab 1; 19-22 - Grab 2; 23-49 - Grab 3 (nach Čujanová-Jílková 1975).

Die genannten Beispiele mögen als Hinweis darauf genügen, dass derartige goldene Lockenringe und andere goldene Accessoires zwar auf den besonderen Rang des männlichen Bestatteten hinweisen, dass aber weder aufgrund ihres Vorkommens noch wegen ihrer Kombination mit unterschiedlichen Waffeninventaren irgendwelche weitergehenden Schlussfolgerungen im Hinblick auf eine eventuelle soziale Differenzierung der mit Waffen bestatteten Männer zu ausreichend zu begründen sind. Vor allem stellt sich wie schon in der Frühbronzezeit die Frage nach dem Verhältnis zu den Bestattungen mit Waffenbeigabe aber ohne derartige goldene Accessoires. Keinesfalls möchte man die "reichen" Gräber wie beispielsweise diejenigen von Letkés, Vatin, Grödig, Göggenhofen, Stáhlavy-Hájek (Hügel 48), Kbel (Hügel 4a), Haidlfing oder Tachlovice allein wegen des Fehlens derartiger Goldobjekte von vornherein herabstufen. Und genauso wenig möchte man weder auf lokaler noch auf überregionaler Ebene eine Abstufung im Rang allein auf Basis der unterschiedlichen Waffenkombinationen vornehmen. Und was nun den auffälligen Befund von Hügel 39 in Sedlec-Hůrka angeht, könnte man 


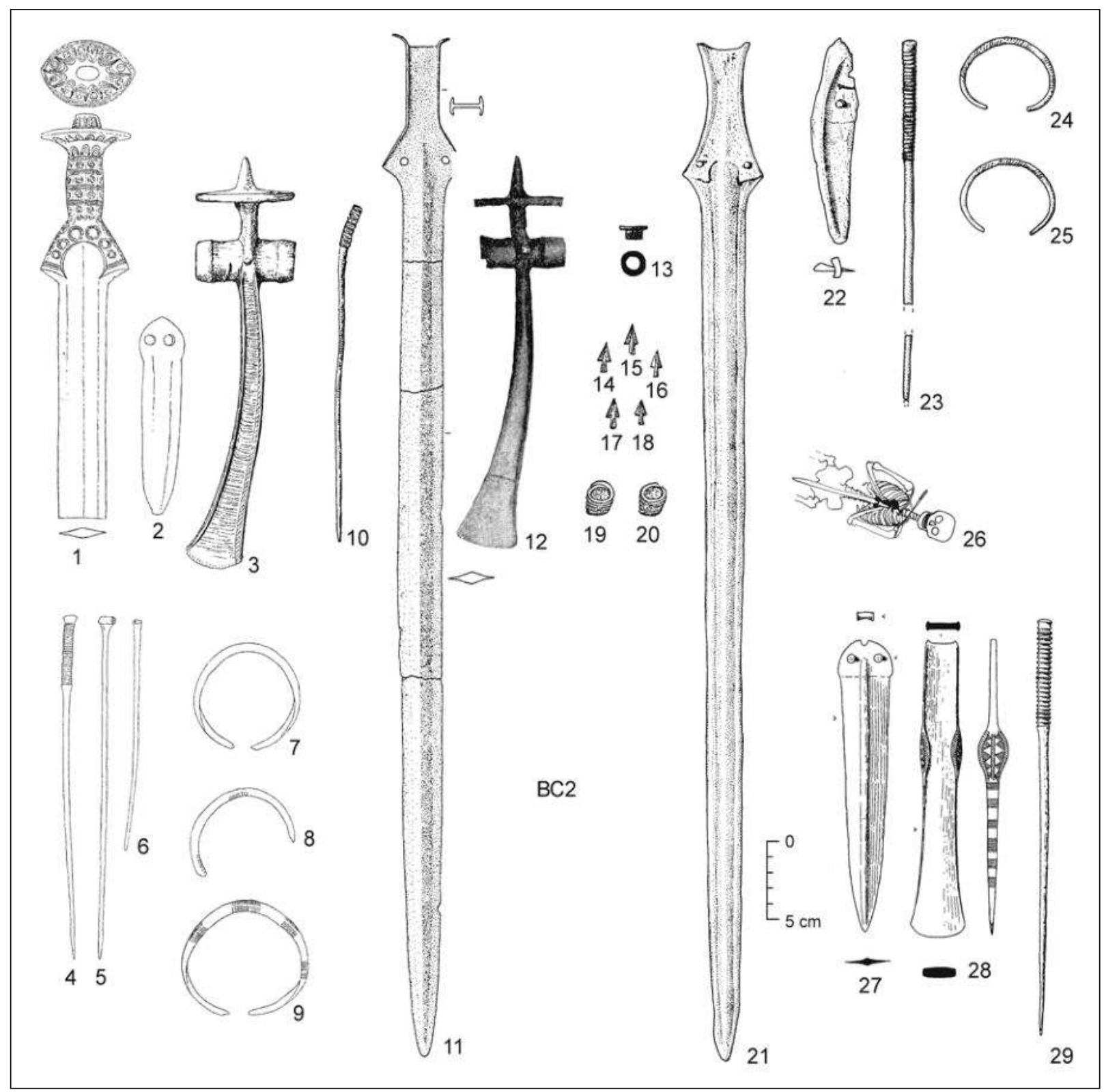

Abb. 9. Grabfunde der Stufe BC2. 1-9 - Tachlovice, Grab; 10-20 - Třebívlice, Grab; 21-26 - Asenkofen, Hügel E, Westhälfte; 27-29 - Kösching, Köschinger Forst-Rehlucke, Grab (nach Beneš 1959; David 2002a; Müller-Karpe 1954; Wenzl 1907).

sich durchaus zu der überaus kühnen Hypothese verführen lassen, dass hier eine „,komplette Ausstattung" aus Schwert, Nackenscheibenaxt und Dolch auf drei Männergräber verteilt erscheint, und zwar aufgeteilt entsprechend der jeweiligen Quantität der diesen Männern beigegebenen Goldfunde und Pfeilspitzen. Eher jedoch dürften die fünf im größten Grabhügel von Sedlec-Hůrka bestatteten Personen bereits durch ihre Bestattung im größten Grabhügel des Gräberfeldes ausreichend hervorgehoben und gewissermaßen auf die gleiche soziale Ebene gestellt gewesen sein.

Die genannten Beispiele zeigen, dass vor allem aufgrund der insgesamt geringen Zahl sicherer Befunde keine signifikanten Beobachtungen zu machen sind, auf denen sich weitergehende Überlegungen zur Gesellschaftsstruktur aufbauen lassen, die auch einer kritischen Betrachtung standhalten. ${ }^{29}$ Keine der

\footnotetext{
${ }^{29}$ Einer solchen kritischen Analyse sind auch die Hypothesen von H. Meller $(2015 ; 2017 ; 2019)$ zu Gesellschaftsstruktur und Militärwesen der Aunjetitzer Kultur Mitteldeutschlands zu unterziehen, die sich ohnehin kaum auf die Regionalgruppen der Aunjetitzer Kultur in Böhmen, Mähren, Schlesien, Niederösterreich und der Südwestslowakei übertragen lassen.
} 
Nekropolen der mittelbronzezeitlichen Hügelgräberkulturen zwischen Süddeutschland und dem Banat bietet eine vergleichsweise breite Quellenbasis wie beispielsweise südlich der Alpen die Nekropole von Olmo di Nogara im norditalienischen Veneto, wo sich etwa zur gleichen Zeit hinsichtlich der Bewaffnung ein einheitliches Bild von mit langen Stichschwertern Bestatteten darbietet, wobei dort im Gegensatz zu den Gebieten nördlich der Alpen und des Karpatenbeckens zudem weder Äxte/Beile noch Lanzenspitzen oder Pfeilspitzen in die Gräber gelangten (David 2020, 215-217, Abb. 4; Salzani ed. 2005).

Nur unter den eingangs erwähnten Vorbehalten lassen sich anhand der in früh- und mittelbronzezeitlichen Gräbern oder Depotfunden des Donauraumes überlieferten Waffen einige Feststellungen zu Bewaffnung oder Kampfesweise treffen: Der Gebrauch des Bogens als Fern- oder Jagdwaffe ist grundsätzlich immer vorauszusetzen, auch wenn in Gräbern der entwickelten und der späten Frühbronzezeit (BA2a-BB-älter) Pfeilspitzen vorübergehend nicht überliefert wurden (David 2014, 191-194; Sicherl 2004, 212). Von der entwickelten Frühbronzezeit (BA2a) bis in die ausgehende Mittelbronzezeit (BC2) belegen Beile und Äxte aus Metall oder Geweih die vorherrschende Stellung von Hiebwaffen. Axt oder Beil werden oft von einem Dolch geringerer Länge begleitet, der im Nahkampf als Stichwaffe einzusetzen war, jedoch auch als Multifunktionsgerät anzusehen ist. Gegen Ende der späten Frühbronzezeit (BA2c/BB-älter) ist das Beil in Gräbern erstmals mit nun deutlich längeren Dolchen oder Kurzschwertern kombiniert. Ein gleichzeitiges Führen von Dolch/Kurzschwert/Schwert und Axt/Beil war generell möglich und erlaubte den effizienten kombinierten Einsatz von Hieb- und Stichwaffen.
Die Verlängerung der Klinge erhöhte die Reichweite der Schwerter und führte zu ihrer Optimierung als Stichwaffe. Doch bedeutete das erste Auftreten von Schwertern am Ende der Frühbronzezeit und zu Beginn der Mittelbronzezeit keine Zäsur in der Tradition der gemeinsamen Verwendung von Hieb- und Stichwaffen oder gar eine Verdrängung von Axt/Beil (Abb. 5; 6). Es gibt zwar auch im Donauraum Gräber, die wie in Olmo di Nogara als einzige Waffe ein Schwert - zuweilen von einem Dolch/Messer begleitet - enthalten. Doch geht mit dem Auftreten von Schwertern ab der späten Frühbronzezeit (BB-älter) kein deutlicher Bedeutungsverlust für Beil/Axt einher. Vielmehr weisen die Grabfunde der entwickelten Hügelgräberkultur mit der Kombination von Schwert/Dolch und Axt/ Beil weiterhin auf einen weitgehend gleichrangigen Einsatz von Hieb- und Stichwaffen hin.

$\mathrm{Ab}$ der späten Mittelbronzezeit (BC2-BD) begann die Entwicklung zu Schwertern, deren Klingen sowohl zum Hieb als auch zum Stich taugten und somit vielseitiger einsetzbar waren als das reine Stichschwert und die zudem als Hiebwaffe eine größere Reichweite als Beil oder Axt besaßen. Erst die Verwendung von Hiebschwertern in der Spätbronzezeit führte zum Verdrängen von Axt/Beil als langer Hiebwaffe. An die Stelle des reinen Stichschwertes trat als lange Stoßwaffe nun die Lanze, die über eine größere Reichweite als jedes Schwert verfügte und die mittels Werfen auch als Fernwaffe auf kurze Distanz einzusetzen war. Die spätbronzezeitlichen Hiebschwerter bildeten schließlich zusammen mit der Lanze, die an Reichweite jedes Schwert übertraf und als „verlängerte Stichwaffe" fungieren konnte, eine äußerst effiziente Kombination von Hieb- und Stichwaffe (Abels 2003, 42; Sicherl 2004, 216, 218). 


\section{LITERATUR}

Abels 2003 - B.-U. Abels: Ein spätbronzezeitliches Griffplattenschwert aus Baunach. Das archäologische Jahr in Bayern 2002, 2003, 41, 42.

Bátora 1982 - J. Bátora: Ekonomicko-sociálny vývoj východného Slovenska v staršej dobe bronzovej. Slovenská archeológia 30, 1982, 249-314.

Bátora 2009a - J. Bátora: Metallurgy and Early Bronze Age Fortified Settlements in Slovakia. Slovenská archeológia 57, 2009, 195-219.

Bátora 2009b - J. Bátora: Hroby s dýkami na pohrebisku zo staršej doby bronzovej v Ludaniciach-Mýtnej Novej Vsi. Slovenská archeológia 57, 2009, 221-260.

Beneš 1959 - A. Beneš: K problémům mohylové kultury doby bronzové ve středních Čechách. Sborník Národního muzea v Praze. Historie 13, 1959, 1-96.

Benkovsky-Pivovarová/Chropovský 2015 - Z. Benkovsky-Pivovarová/B. Chropovský: Grabfunde der frühen und der beginnenden mittleren Bronzezeit in der Westslowakei. Teil 1-2. Archaeologica Slovaca Monographiae. Studia 22. Nitra 2015.

Bóna 1975 - I. Bóna: Die mittlere Bronzezeit im Karpatenbecken und ihre südöstlichen Beziehungen. Archaeologia Hungarica 49. Budapest 1975 .

Čujanová-Jílková 1970 - E. Čujanová-Jílková: Mittelbronzezeitliche Hügelgräberfelder in Westböhmen. Archeologické studijní materiály 8. Praha 1970.

Čujanová-Jílková 1975 - E. Čujanová-Jílková: Zlaté předměty v hrobech českofalcké mohylové kultury. Památky archeologické 66, 1975, 74-132.

David 1998a - W. David: Zum Ende der bronzezeitlichen Tellsiedlungen im Karpatenbecken. In: H. Küster/ A. Lang/P. Schauer (Hrsg.): Archäologische Forschungen in urgeschichtlichen Siedlungslandschaften. Festschrift für Georg Kossack zum 75. Geburtstag. Regensburger Beiträge zur prähistorischen Archäologie 5. Regensburg 1998, 231-267.

David 1998b - W. David: Zu Variantengliederung, Verbreitung und Datierung der kosziderzeitlichen Sichelnadeln. In: H. Ciugudean/F. Gogâltan (eds.): The Early and Middle Bronze Age in the Carpathian Basin. International Symposium, Alba Iulia, September 24-28, 1997. Bibliotheca Musei Apulensis 8. Alba Iulia 1998, 281-370.

David 1998c - W. David: Zu früh- und ältermittelbronzezeitlichen Grabfunden in Ostbayern. In: J. Michálek/ K. Schmotz/M. Zápotocká (Hrsg.): Archäologische Arbeitsgemeinschaft Ostbayern/West- und Südböhmen. 7. Treffen 11. bis 14. Juni 1997 in Landau an der Isar. Resümees der Vorträger. Rahden/Westf. 1998, 108-129.

David 2002a - W. David: Studien zu Ornamentik und Datierung der bronzezeitlichen Depotfundgruppe Hajdúsámson-Apa-Ighiel-Zajta. Bibliotheca Musei Apulensis 18. Alba Iulia (Karlsburg/Weissenburg) 2002.

David 2002b - W. David: Bayern und Böhmen zwischen Ost und West während früher und mittlerer Bronzezeit. In: M. Chytráček/J. Michálek/K. Schmotz (Hrsg.): Archäologische Arbeitsgemeinschaft Ostbayern/West- und Südböhmen. 11. Treffen 20. bis 23. Juni 2001 in Obernzell. Rahden/Westf. 2002, 62-93.

David 2008 - W. David: Älterbronzezeitliche Depotfunde Ostbayerns im Lichte ihrer überregionalen Bedeutung. In: K. Schmotz (Hrsg): Vorträge des 26. Niederbayerischen Archäologentages. Rahden/West. 2008, 197-237.
David 2009 - W. David: Nascita e crollo della civiltà dei Tell dell ’antica età del Bronzo nel bacino carpatico ed indizi di possibili, analoghi fenomeni culturali coevi nella regione dell'alto e medio Danubio nella prima metà del II millenio a.C. In: A. Cardarelli/A. Cazzella/ M. Frangipane/R. Peroni (eds.): Reasons for change. Birth, decline and collapse of societies between the end of the IV and the beginning of the I millennium B.C. Atti del convegno internazionale, La Sapienza, Roma, 15-17 giugno 2006. Scienze dell'Antichità. Storia - Archeologia - Antropologia 15. Roma 2009, 563-594.

David 2013 - W. David: Eine mit Spiralhakenranken verzierte altbronzezeitliche Nackenkammaxt siebenbürgischen Typs aus Südwestböhmen. Wo wurden die Schaftlochäxte vom Typ Apa-Nehoiu hergestellt? In: B. Rezi/R. E. Németh/S. Berecki (eds.): Bronze Age Crafts and Craftsmen in the Carpathian Basin. Proceedings of the International Colloquium from Târgu Mureş 5-7 October 2012. Târgu Mures 2013, 91-138.

David 2014 - W. David: Von Raisting bis Deggendorf-Fischerdorf - Zur Bewaffnung der Früh- und Mittelbronzezeit in Bayern. In: L. Husty/W. Irlinger/J. Pechtl (Hrsg.): „,... und es hat doch was gebracht!". Festschrift für Karl Schmotz zum 65. Geburtstag. Internationale Archäologie. Studia Honoria 35. Rahden/Westf. 2014, 187-206.

David 2015 - W. David: Bronzedepotfunde der Früh- und Mittelbronzezeit in Ostbayern. Fines Transire 24, 2015, 87-111.

David 2019 - W. David: Der frühbronzezeitliche Fund von Ried im Tiroler Oberinntal. In: S. Hye/U. Töchterle (Hrsg.): UPIKU:TAUKE. Festschrift für Gerhard Tomedi zum 65. Geburtstag. UPA 339. Bonn 2019, 87-101.

David 2020 - W. David: L'Italia settentrionale tra il sud del centro Europa ed il Bacino Carpatico. Contatti transalpini nella prima metà del secondo millennio $\mathrm{BC}$ tra Pianura Padana e alto e medio Danubio. In: M. Bernabo Brea (ed.): Italia tra Mediterraneo ed Europa: mobilità, interazioni e scambi. Rivista di Scienze Preistoriche 70/ S1 - numero speciale. Firenze 2020, 219-230.

David u. a. 2017 - W. David/M. David-Elbiali/R. de Marinis/M. Rapi: Le Bronze moyen et récent entre Italie du Nord, Suisse et Allemagne du Sud: corrélation des systèmes chrono-culturels. In: T. Lachenal/ C. Mordant/T. Nicolax/C. Véber (éds.): Le Bronze moyen et l'origine du Bronze Final en Europe occidentale (XVII ${ }^{e}-X I I I^{e}$ siècle av. J.-C.). Actes de colloque ABRAB 'Bronze 2014', Strasbourg, 17-20 juin 2014. Strasbourg 2017, 565-600.

David-Elbiali/David 2009 - M. David-Elbiali/W. David: À la suite de Jacques-Pierre Millotte, l'actualité des recherches en typologie sur l'age du Bronze, le Bronze ancien et le début du Bronze moyen: cadre chronologique et liens culturels entre l'Europe nord-alpine occidentale, le monde danubien et l'Italie du Nord. In: A. Richard/P. Barral/A. Daubigney/G. Kaernel/ C. Morfant/J.-F. Piningre (éds.): L'isthme européen Rhin-Saône-Rhône dans la Protohistoire. Approches nouvelles en hommage à Jacques-Pierre Millotte, Besançon, 16-18 octobre 2006. Besançon 2009, 295-324.

Hampl/Kerchler/Benkovsky-Pivovarová 1981 - F. Hampl/ H. Kerchler/Z. Benkovsky-Pivovarová: Das mittelbronzezeitliche Gräberfeld von Pitten in Niederösterreich. Band 1: Fundberichte und Tafeln. Mitteilungen der Prähistorischen 
Kommission der Österreichischen Akademie der Wissenschaften 19-20. Wien 1981.

Harding 2007 - A. Harding: Warriors and weapons in Bronze Age Europe. Archaeolingua Series Minor 25. Budapest 2007.

Hrala 1997 - J. Hrala: Gold der mittleren Bronzezeit und Urnenfelderzeit: Böhmen. In: G. Lehrberger/J. Fridrich/ R. Gebhard/J. Hrala (Hrsg.): Das prähistorische Gold in Bayern, Böhmen und Mähren. Herkunft - Technologie Funde. Památky archeologické. Supplementum 7. Praha 1997, 169-189.

Hochstetter 1980 - A. Hochstetter: Die Hügelgräberbronzezeit in Niederbayern. Materialhefte zur bayerischen Vorgeschichte 41. Kallmünz/Opf. 1980.

Jockenhövel 2006 - A. Jockenhövel: Zur Archäologie der Gewalt: Bemerkungen zu Aggression und Krieg in der Bronzezeit Europas. In: M. Novotná (ed.): Arms and Armour through the Ages (From the Bronze Age to the Late Antiquity). Proceeding of the International Symposium, Modra-Harmónia, 19-22 November 2005. Anodos. Studies of the Ancient World 4-5, 2004-2005 (2006), Trnava 2006, 101-132.

Kaiser 1962 - G. Kaiser: Das frühbronzezeitliche Gräberfeld von Unterwölbling, p.B. St. Pölten, N.Ö. Archaeologia Austriaca 31, 1962, 35-61.

Kiss 2020 - V. Kiss: The Bronze Age Burial from Balatonakali Revisited. In: J. Maran/R. Băjenaru/S.-C. Ailincăi/A.-D. Popescu/S. Hansen (eds.): Objects, Ideas and Travelers. Contacts between the Balkans. The Aegean and Western Anatolia during the Bronze and Early Iron Age. UPA 350. Bonn 2020, 529-544.

Koschik 1981 - H. Koschik: Die Bronzezeit im südwestlichen Oberbayern. Materialhefte zur bayerischen Vorgeschichte 50. Kallmünz/Opf. 1981.

Kovács 1982 - T. Kovács: Einige neue Angaben zur Ausbildung und inneren Gliederung der Füzesabony-Kultur. In: B. Hänsel (Hrsg.): Südosteuropa zwischen 1600 und 1000 v. Chr. PAS 1. Berlin 1982, 287-304.

Kovács 1995 - T. Kovács: Auf Mitteleuropa weisende Beziehungen einiger Waffenfunde aus dem östlichen Karpatenbecken. In: B. Hänsel (Hrsg.): Handel, Tausch und Verkehr im bronze- und früheisenzeitlichen Europa. PAS 11. München - Berlin 1995, 173-185.

Kovács 1996 - T. Kovács: The Tumulus Culture in the Middle Danube Region and the Carpathian Basin: Burials of the Warrior Élite. In: C. Belardelli/R. Peroni (eds.): The Bronze Age in Europe and the Mediterranean. The Colloquia of the XIII International Congress of Prehistoric and Protohistoric Sciences 11. Forlì 1996, 113-126.

Massy u. a. 2018 -K. Massy/S. Hanöffner/N. Carlichi-Witjes/ Ph. W. Stockhammer: Früh- und ältermittelbronzezeitliche Gräber und Siedlungsreste aus Altenmarkt, Stadt Osterhofen, Lkr. Deggendorf. In: L. Husty/K. Schmotz (Hrsg): Vorträge des 36. Niederbayerischen Archäologentages. Rahden/Westfalen 2018, 123-174.

Meller 2015 - H. Meller: Armeen in der Frühbronzezeit? In: H. Meller/M. Schefzik (Hrsg.): Krieg - Eine archäologische Spurensuche. Begleitband zur Sonderausstellung im Landesmuseum für Vorgeschichte Halle (Saale). Halle (Saale) 2015, 243-252.

Meller 2017 - H. Meller: Armies in the Early Bronze Age? An alternative interpretation of Únětice Culture axe hoards. Antiquity 91, 2017, 1529-1545.
Meller 2019 - H. Meller: Princes, Armies, Sanctuaries. The Emergence of Complex Authority in the Central German Unětice Culture. Acta Archaeologica 90, 2019, 39-79.

Müller-Karpe 1954 - H. Müller-Karpe: Metallzeitliche Funde aus Süddeutschland. Inventaria Archaeologica Deutschland 2. Bonn 1954.

Neugebauer 1991 - J.-W. Neugebauer: Die Nekropole F von Gemeinlebarn, Niederösterreich. Untersuchungen zu den Bestattungssitten und zum Grabraub in der ausgehenden Frühbronzezeit in Niederösterreich südlich der Donau zwischen Enns und Wienerwald. Römisch-Germanische Forschungen 49. Mainz 1991.

Neugebauer/Gattringer 1989 - J.-W. Neugebauer/A. Gattringer: Rettungsgrabungen im Unteren Traisental im Jahre 1988. Fundberichte aus Österreich 27, 1989, 65-98.

Neugebauer/Neugebauer 1997 - C. Neugebauer/J.-W. Neugebauer: Franzhausen. Das frühbronzezeitliche Gräberfeld I. Fundberichte aus Österreich. Materialheft 5. Horn 1997.

Ohrenberger 1953 - A. J. Ohrenberger: Das bronzezeitliche Grab von Zurndorf, Burgenland. In: F. Holste: Die bronzezeitlichen Vollgriffschwerter Bayerns. Münchner Beiträge zur Vor- und Frühgeschichte 4. München 1953, 37-39.

Olexa/Nováček 2015 - L. Olexa/T. Nováček: Pohrebisko zo staršej doby bronzovej v Nižnej Myšli. Katalóg II (hroby 311-499). Archaeologica Slovaca Monographiae. Catalogi 15. Nitra 2015.

Popescu 1940 - D. Popescu: Dépôt de bronzes de Apa. Dacia 7-8, 1937-1940, 119-125.

Reinecke 1905 - P. Reinecke: Zwei Grabfunde der älteren Bronzezeit aus Oberbayern. Altbayerische Monatsschrift 5, 1905, 110-118.

Rieckhoff 1990 -S. Rieckhoff: Faszination Archäologie. Bayern vor den Römern. Regensburg 1990.

Ruckdeschel 1978 - W. Ruckdeschel: Die frühbronzezeitlichen Gräber Südbayerns. Ein Beitrag zur Kenntnis der Straubinger Kultur. Bonn 1978.

Ruckdeschel 1985-W. Ruckdeschel: Das frühbronzezeitliche Gräberfeld von Mintraching, Ldkr. Regensburg. Bayerische Vorgeschichtsblätter 50, 1985, 127-182.

Říhovský 1992 - J. ̌̌íhovský, Die Äxte, Beile, Meißel und Hämmer in Mähren. PBF IX/17. Stuttgart 1992.

Salzani ed. 2005 - L. Salzani ed.: La necropoli dell'età del Bronzo all'Olmo di Nogara. Memorie del Museo Civico di Storia Naturale di Verona II/8. Verona 2005.

Schauer 1971 - P. Schauer: Die Schwerter in Süddeutschland, Österreich und der Schweiz I. PBF IV/2. München 1971.

Schröter 1998 - P. Schröter: Ein neues frühbronzezeitliches Gräberfeld im Donaubogen bei Regensburg: Mötzing, Lkr. Regensburg. In: J. Michálek/K. Schmotz/M. Zápotocká (Hrsg.): Archäologische Arbeitsgemeinschaft Ostbayern/West- und Südböhmen. 7. Treffen 11. bis 14. Juni 1997 in Landau an der Isar. Resümees der Vorträger. Rahden/ Westf. 1998, 102-107.

Schubert 1973 - E. Schubert: Studien zur frühen Bronzezeit an der mittleren Donau. Bericht der Römisch-Germanischen Kommission 54, 1973, 1-105.

Sicherl 2004 - B. Sicherl: Studien zur mittelbronzezeitlichen Bewaffnung in Tschechien, dem nördlichen Niederösterreich und der südwestlichen Slowakei. UPA 107. Bonn 2004.

Stuchlík 2006 - S. Stuchlík: Borotice. Mohylové pohřebiště $z$ doby bronzové. Spisy Archeologického ústavu AV ČR 30. Brno 2006. 
Szatmári 2018 - I. Szatmári: On the metallurgy of the Füzesabony-Culture. Bronze finds and casting moulds from the Füzesabony Bronze Age tell settlement. Communicationes Archaeologicae Hungariae 2017, 2018, 51-79.

Torbrügge 1959 - W. Torbrügge: Die Bronzezeit in der Oberpfalz. Materialhefte zur bayerischen Vorgeschichte 13. Kallmünz/Opf. 1959.

Torma 1978 - I. Torma: A balatonakali bronzkori sír. A Veszprém Megyei Múzeumok Közleményei 13, 1978, 15-27.

Vahlkampf 1984 - G. Vahlkampf: Das mittelbronzezeitliche Vollgriffschwert aus Zurndorf. Wissenschaftliche Arbeiten aus dem Burgenland 69, 1984, 38-42.

Manuskript angenommen am 1.9. 2020

Abstract translated by Wolfgang David

Súhrn preložila Anita Kozubová
Wels-Weyrauch 2015 - U. Wels-Weyrauch: Die Dolche in Bayern. PBF VI/15. Stuttgart 2015.

Wenzl 1907 - J. Wenzl: Über die Ausgrabungen bei Asenkofen. Beiträge zur Anthropologie und Urgeschichte Bayerns $16,1907,85-116$.

Zich 2016 - B. Zich: Aunjetitzer Herrschaften in Mitteldeutschland - „Fürsten“ der Frühbronzezeit und ihre Territorien („Domänen“). In: H. Meller/H. P. Hahn/ R. Jung/R. Risch (Hrsg.): Arm und Reich. Zur Ressourcenverteilung in prähistorischen Gesellschaften. 8. Mitteldeutscher Archäologentag, 22.-24. Oktober 2015, Halle (Saale). Tagungen des Landesmususeums für Vorgeschichte 14. Halle (Saale) 2016, 371-406.

Dr. Wolfgang David M.A.

Archäologisches Museum Frankfurt

Karmelitergasse 1

D - 60311 Frankfurt am Main

wolfgang.david@stadt-frankfurt.de

\title{
Zbrane $\mathrm{v}$ hroboch zo staršej a strednej doby bronzovej $\mathrm{z}$ horného a stredného Podunajska
}

\author{
Wolfgang David
}

\section{SÚHRN}

Akékolvvek konštatovania o výzbroji v staršej a strednej doby bronzovej v regióne horného a stredného Podunajska sa zakladajú výlučne na nálezoch z hrobov a depotov.

V zásade sa predpokladá, že luk ako dial'ková alebo lovecká zbraň sa používal počas celej doby bronzovej. Od klasickej fázy staršej doby bronzovej (BA2a) až po neskorú fázu strednej doby bronzovej (BC2) prevažujú vo výzbroji zo sledovaného priestoru sečné zbrane $\mathrm{v}$ podobe sekier vyrobených z kovov alebo z parohov. Sekery boli v hroboch často sprevádzané dýkami, ktoré sa používali ako bodná zbraň v boji z blízka. Tie boli zároveň multifunkčnými predmetmi. Na konci mladšej doby bronzovej (BA2c/BB) dochádza k zefektívneniu výzbroje v podobe kombinácie sečných a bodných zbraní - sekery sa v hroboch prvýkrát vyskytli s podstatne dlhšími dýkami alebo s krátkymi mečmi. Prvý výskyt mečov v závere staršej doby bronzovej (BB) ale nijako výrazne neubral na dôležitosti sekier vo výzbroji doby bronzovej. Hrobové celky mohylovej kultúry s kombináciou meč/dýka a sekera (BC), naopak, potvrdzujú rovnakú dôležitost’ sečných a bodných zbraní vo výzbroji zo priestoru. Od záveru strednej doby bronzovej (BC2-BD) pozorujeme vývoj mečov s čepelami vhodnými na sekanie a bodanie. Až použitie takýchto sečných mečov v kombinácii s kopijami/oštepmi ako bodnými zbraňami viedlo od stupňa BD k postupnému nahrádzaniu sekier ako sečných zbraní. 
